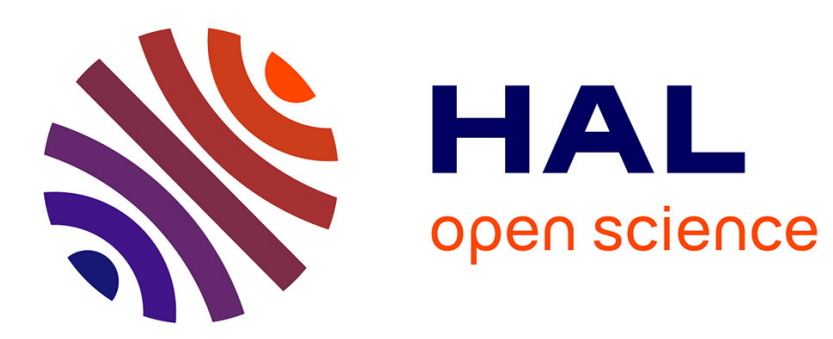

\title{
On the Probabilistic-Deterministic Transition Involved in a Fragmentation Process of Brittle Materials
} François Hild, Christophe Denoual, Pascal Forquin, Xavier Brajer

\section{To cite this version:}

François Hild, Christophe Denoual, Pascal Forquin, Xavier Brajer. On the Probabilistic-Deterministic Transition Involved in a Fragmentation Process of Brittle Materials. Computers \& Structures, 2003, 81, pp.1241-1253. 10.1016/S0045-7949(03)00039-7 . hal-00002910

\section{HAL Id: hal-00002910 https://hal.science/hal-00002910}

Submitted on 20 Sep 2004

HAL is a multi-disciplinary open access archive for the deposit and dissemination of scientific research documents, whether they are published or not. The documents may come from teaching and research institutions in France or abroad, or from public or private research centers.
L'archive ouverte pluridisciplinaire HAL, est destinée au dépôt et à la diffusion de documents scientifiques de niveau recherche, publiés ou non, émanant des établissements d'enseignement et de recherche français ou étrangers, des laboratoires publics ou privés. 


\title{
On the Probabilistic-Deterministic Transition Involved in a Fragmentation Process of Brittle Materials
}

\author{
François Hild, ${ }^{\mathrm{a}, 1}$ Christophe Denoual, ${ }^{\mathrm{b}}$ Pascal Forquin ${ }^{\mathrm{c}}$ \\ and Xavier BRAJER ${ }^{\mathrm{d}}$ \\ ${ }^{\text {a } L M T-C a c h a n ~}$ \\ ENS de Cachan / CNRS-UMR 8535 / Université Paris 6 \\ 61 avenue du Président Wilson, F-94235 Cachan Cedex, France. \\ ${ }^{\mathrm{b}}$ CEA/DAM-Département PTA \\ BP 12, F-91680 Bruyères le Chatel Cedex, France. \\ ${ }^{\mathrm{c}} D G A / C T A$-Département MSP \\ 16 bis avenue Prieur de la Côte d'Or, F-94114 Arcueil Cedex, France. \\ ${ }^{\mathrm{d}}$ Saint-Gobain Recherche \\ 39 quai Lucien Lefranc, F-93303 Aubervilliers Cedex, France.
}

\begin{abstract}
Dynamic loadings produce high stress waves leading to the fragmentation of brittle materials such as ceramics, concrete, glass and rocks. The main mechanism used to
\end{abstract}


explain the change of the number of fragments with stress rate is a shielding phenomenon. However, under quasi-static loading conditions, a weakest link hypothesis may be applicable. Therefore, depending on the local strain or stress rate, different fragmentation regimes are observed. One regime corresponds to single fragmentation for which a probabilistic approach is needed. Conversely, the multiple fragmentation regime may be described by a deterministic approach. The transition between the two fragmentation regimes is discussed for high performance concrete, glass and $\mathrm{SiC}$ ceramics.

Keywords: Brittle materials, Continuum Damage Mechanics, discrete modeling, dynamic fracture, probability and statistics, single and multiple fragmentation, stress relaxation, Weibull model.

\section{Introduction}

A consequence of intense pulses on brittle materials is their fragmentation into discrete domains. For example, ceramics can be multiply fragmented when impacted [1]. This class of materials has received some attention when used as a front layer of an armor [2,3]. Similarly, glass is used in armored windshields and can experience multiple fragmentation when impacted by debris or bullets $[4,5]$. Furthermore, since the pioneering work of Rinehart [6], it is known that the ultimate strength of rocks under so-called dynamic loading conditions exceeds the static strength by as much as one order of magnitude. The distinct zones resulting from rock blasting were clearly identified by Kutter

$\overline{1}$ to whom correspondence should be addressed. Fax: $+33 \quad 147402240$ Email: hild@lmt.ens-cachan.fr. 
and Fairhurst [7], namely a comminuted area in the vicinity of the explosive followed by a damaged zone in which dense microcracking is observed and finally a zone where few long cracks develop. Later, it was recognized that inherent flaws are activated, can grow and eventually coalesce to form macrocracks [8]. Similarly, concrete can experience multiple fragmentation when hit by a projectile [9]. Yet, when loaded in tension or flexure under quasi-static conditions, the same materials usually experience single fragmentation and their failure strength is no longer deterministic. The aim of the present paper is to discuss the reasons for this difference in behavior and to propose criteria as well as numerical strategies to account for the latter.

The fragmentation process is discrete by essence. In the theory developed by Mott [10], the fragmentation of a rapidly expanding ring was studied. Even though it is based on some heuristics, its contains some key ingredients (i.e., the randomness of the process is clearly stated and accounted for) to analyze the distribution of fragments in 2D experiments [11]. From a numerical point of view, discrete modelings are also proposed [12-14] when the fragment size is greater than or equal to the size of a representative element. Espinosa et al. [15] have developed a continuum/discrete multi-scale model in which the finer scale is discrete and allows for the derivation of a continuum description on a higher scale. Alternatively, Continuum Damage Mechanics can be used with an isotropic [16-18] or anisotropic [19] damage description to account for multiple fragmentation. Consequently, in the numerical simulations, the medium is assumed to be continuum on the scale of a finite element in which numerous cracks are expected to form.

However, crack densities may strongly vary over the structure and the analysis of fragmentation through a continuum modeling may be delicate when one or 
a few cracks are nucleated or propagate in certain zones. As an alternative, a multi-scale model has been developed in which the probabilistic aspect is treated within a damage model [20,21]. The aim of the present paper is to introduce relevant parameters that enable the user to choose between continuum and discrete approaches. Section 2 introduces a fragmentation model accounting for quasi-static and dynamic loading conditions. It is shown that a Poisson-Weibull framework is convenient to derive closed-form solutions. Characteristic parameters are introduced in Section 3. They depend on material properties (i.e., Weibull parameters) and loading conditions (i.e., strain or stress rate). A criterion is derived to discuss the transition between single and multiple fragmentation in terms of the characteristic parameters. Based upon the fragmentation theory, a so-called multi-scale damage model [21] is summarized in Section 4. This model is used to analyze different fragmentation conditions of brittle materials. Section 5 deals with the stress or strain rate sensitivity of the ultimate tensile strength of high performance concrete. Section 6 discusses the transition in terms of ultimate strength and toughness of soda lime silica glass. Finally, in Section 7, the simulation of a so-called Edge-On Impact configuration [4] is discussed. In particular, the fact that the transition criterion can be used to analyze damage localization is analyzed for two $\mathrm{SiC}$ grades.

\section{Fragmentation of Brittle Materials}

For brittle materials, the analysis of failure depends upon the microstructure in terms of flaw density and failure stress distribution [8]. The microstructure is approximated by point defects of density $\lambda_{\mathrm{t}}$ with random locations. It can 
be described by a Poisson point process of intensity $\lambda_{\mathrm{t}}[22,23]$

$$
\lambda_{\mathrm{t}}(\sigma)=\lambda_{0}\left(\frac{\langle\sigma\rangle}{\sigma_{0}}\right)^{m}
$$

where $m$ is the Weibull modulus, $\sigma$ a local stress to be specified later on, $\sigma_{0}$ the scale parameter relative to a reference density $\lambda_{0},\langle\star\rangle$ the Macauley brackets (i.e., the positive part of $\star$ ). The constant $\lambda_{0} / \sigma_{0}^{m}$ is the Weibull scale parameter. Equation (1) shows that the higher the local stress $\sigma$, the more defects can break. The probability $P$ of finding $N=B$ broken defects within a uniformly loaded domain $\Omega$ is expressed in terms of a Poisson distribution

$$
P(N=B)=\frac{\left[\lambda_{\mathrm{t}}(\sigma) Z\right]^{B}}{B !} \exp \left[-\lambda_{\mathrm{t}}(\sigma) Z\right]
$$

The product $\lambda_{\mathrm{t}}(\sigma) Z$ corresponds to the average number of broken defects within a domain $\Omega$ of volume, surface or length $Z$. Within the weakest link framework [24], the failure probability $P_{\mathrm{F}}$ is the probability of finding at least one broken defect in a domain $\Omega$

$$
P_{\mathrm{F}}=P(N \geq 1)=1-P(N=0)=1-\exp \left[-Z \lambda_{0}\left(\frac{\langle\sigma\rangle}{\sigma_{0}}\right)^{m}\right]
$$

When the domain is not uniformly loaded, the failure probability can be written as

$$
P_{\mathrm{F}}=1-\exp \left[-Z_{\mathrm{eff}} \lambda_{0}\left(\frac{\left\langle\sigma_{\mathrm{F}}\right\rangle}{\sigma_{0}}\right)^{m}\right],
$$

where $Z_{\text {eff }}$ denotes the effective volume, surface or length [25]

$$
Z_{\mathrm{eff}}=\int_{\Omega}\left[\frac{\sigma^{\star}(\boldsymbol{x})}{\sigma_{\mathrm{F}}}\right]^{m} \mathrm{~d} \boldsymbol{x} \text { with } \sigma_{\mathrm{F}}=\max _{\Omega} \sigma^{\star}(\boldsymbol{x}),
$$

corresponding to an equivalent stress $\sigma^{\star}$ (e.g., maximum principal stress) at a given point $\boldsymbol{x}$. Figure 1 shows experimental results in three-point flexure of a $\mathrm{SiC}$ ceramic. A typical sintering defect is also shown. In this first regime, a single local event, i.e., one crack nucleates and traverses the whole structure, 
leads to the failure of the latter. It will be referred to as single fragmentation regime.

Conversely, under impact, a whole cracking pattern is observed [26,27]. It will be referred to as multiple fragmentation regime. In the following, it is assumed that the defect population leading to damage and failure is identical when the material is subjected to quasi-static and dynamic loading conditions [8,28]. To understand why a crack nucleates, one has to model the interaction of a nucleated defect and other defects that would nucleate. The crack propagation velocity is assumed to be constant and equal to a fraction $k$ of the longitudinal wave speed $C_{0}[29,16,27]$. Therefore, one may define a relaxation or obscuration domain of measure $Z_{\mathrm{o}}$ around a crack (i.e., a zone in which the stresses are less than the applied stresses, thus do not cause new crack initiations)

$$
Z_{\mathrm{o}}=S\left[k C_{0}(T-t)\right]^{n}
$$

which is a function of a shape parameter $S$, the present time $T$ and the time to nucleation $t<T$, and the space dimension $(n=1,2$ or 3$)$. The shape parameter $S$ may depend on the Poisson's ratio $\nu$ but it is independent of time so that the relaxed zones are self-similar. New cracks will initiate only if the defect exists in the considered zone and if the flaw does not belong to any relaxed zone. Therefore, the total flaw density $\lambda_{\mathrm{t}}$ can be split into two parts: namely, $\lambda_{\mathrm{b}}$, the broken flaw density and the obscured flaw density. The increment of the broken defect $\lambda_{\mathrm{b}}$ density can be related to that of total flaw density $\lambda_{\mathrm{t}}$ by

$$
\frac{\mathrm{d} \lambda_{\mathrm{b}}}{\mathrm{d} t}=\frac{\mathrm{d} \lambda_{\mathrm{t}}}{\mathrm{d} t} \times\left(1-P_{\mathrm{o}}\right)
$$

with $\lambda_{\mathrm{b}}(0)=\lambda_{\mathrm{t}}(0)=0$ and $P_{\mathrm{o}}$ the probability of obscuration [30]

$$
P_{\mathrm{o}}=1-\exp \left[-\widehat{Z}_{\mathrm{o}}(T) \lambda_{\mathrm{t}}\{\sigma(T)\}\right],
$$


where $\widehat{Z}_{\mathrm{o}}$ is the measure of the mean obscuration zone

$$
\widehat{Z}_{\mathrm{o}}(T) \lambda_{\mathrm{t}}\{\sigma(T)\}=\int_{0}^{T} Z_{\mathrm{o}}(T-t) \frac{\mathrm{d} \lambda_{\mathrm{t}}}{\mathrm{d} t}\{\sigma(t)\} \mathrm{d} t
$$

Equation (8) is an extension of the classical Weibull law (3). In particular, when the stress rate is small enough, only one defect leads to failure and $\widehat{Z}_{\mathrm{o}}=Z$ and Eqn. (3) applies. It can be noted that Eqn. (8) accounts for overlappings of obscuration zones. Furthermore, in the context of mathematical morphology, the above-described approach is nothing but a boolean islands model $[31,32]$.

\section{Characteristic Parameters and Fragmentation Transition}

Let us now consider a case with a constant stress rate $\mathrm{d} \sigma / \mathrm{d} t=\dot{\sigma}$. One can define a dimensionless flaw density $\left(\bar{\lambda}=\lambda / \lambda_{\mathrm{c}}\right)$, time $\left(\bar{t}=t / t_{\mathrm{c}}\right)$, zone size $\left(\bar{Z}=Z / Z_{\mathrm{c}}\right)$ and stress $\left(\bar{\sigma}=\sigma / \sigma_{\mathrm{c}}\right)$ from the condition

$$
\lambda_{\mathrm{c}} Z_{\mathrm{c}}=1 \text { with } \lambda_{\mathrm{c}}=\lambda_{\mathrm{t}}\left[\sigma\left(t_{\mathrm{c}}\right)\right] \text { and } Z_{\mathrm{c}}=Z_{\mathrm{o}}\left(t_{\mathrm{c}}\right) \text {, }
$$

where the subscript ' $c$ ' denotes characteristic quantities. A characteristic stress is defined by $\sigma_{\mathrm{c}}=\dot{\sigma} t_{\mathrm{c}}$. Equation (10) expresses the fact that the characteristic zone size $Z_{\mathrm{c}}$ contains on average one flaw that may break at the characteristic time $t_{\mathrm{c}}$. By using Eqns. (1) and (10), the characteristic parameters are given by

$$
\begin{gathered}
t_{\mathrm{c}}=\left[\frac{\sigma_{0}^{m}}{\lambda_{0} S\left(k C_{0}\right)^{n} \dot{\sigma}^{m}}\right]^{\frac{1}{m+n}}, Z_{\mathrm{c}}=\left[\frac{\left(\sigma_{0} k C_{0}\right)^{m} S^{m / n}}{\lambda_{0} \dot{\sigma}^{m}}\right]^{\frac{n}{m+n}} \\
\sigma_{\mathrm{c}}=\left[\frac{\sigma_{0}^{m} \dot{\sigma}^{n}}{\lambda_{0} S\left(k C_{0}\right)^{n}}\right]^{\frac{1}{m+n}}
\end{gathered}
$$


and a closed-form solution can be derived for Eqn. (7)

$$
\bar{\lambda}_{\mathrm{b}}(\bar{T})=\frac{m}{m+n}\left[\frac{(m+n) !}{n ! m !}\right]^{\frac{m}{m+n}} \gamma\left[\frac{m}{m+n}, \frac{n ! m !}{(m+n) !} \bar{T}^{m+n}\right]
$$

where $\gamma$ is the incomplete gamma function. Equation (12) is the exact solution to Mott's problem extended to 2D and 3D cases with an initial flaw density modeled by a power law function. Figure 2 shows the change of the dimensionless density $\bar{\lambda}_{\mathrm{b}}$ with the dimensionless time $\bar{T}$. When the time $\bar{T}<1$, virtually no obscuration is observed, i.e., $P_{\mathrm{o}} \approx 0$ and $\bar{\lambda}_{\mathrm{b}} \approx \bar{\lambda}_{\mathrm{t}}$. Conversely, when $\bar{T} \gg 1$, $P_{\mathrm{o}} \approx 1$ and saturation occurs. The higher the Weibull modulus $m$, the higher the density at saturation.

A similar study is now carried out to determine the ultimate strength properties. Under quasi-static loading condition, a Weibull model (3) is applied. It follows that the mean failure stress $\sigma_{\mathrm{w}}$ and the corresponding standard deviation $\sigma_{\mathrm{sd}}$ are given by

$$
\sigma_{\mathrm{w}}=\frac{\sigma_{0}}{\left(Z_{\mathrm{eff}} \lambda_{0}\right)^{\frac{1}{m}}} \Gamma\left(1+\frac{1}{m}\right), \sigma_{\mathrm{sd}}^{2}=\frac{\sigma_{0}^{2}}{\left(Z_{\mathrm{eff}} \lambda_{0}\right)^{\frac{2}{m}}} \Gamma\left(1+\frac{2}{m}\right)-\sigma_{\mathrm{w}}^{2}
$$

It is expected that these quantities are the key parameters for low stress rates. In particular, no stress rate effect is obtained when sub-critical crack growth does not occur [33]. A first order approximation of the coefficient of variation (i.e., $\left.\sigma_{\mathrm{sd}} / \sigma_{\mathrm{w}}\right)$ is given by $\pi /(\sqrt{6} m)$; it follows that the higher $m$, the lower the scatter.

The variable $P_{\mathrm{o}}$ can be used to define a damage variable in the framework of Continuum Damage Mechanics [30]. Under quasi-static loading condition, there is a sudden change between the virgin material (i.e., $D=0$ ) and a fully broken brittle material (i.e., $D=1$ ). This case can be studied by using an 
ad hoc formulation [34,35]. Under dynamic loading conditions, there is a more gradual kinetics. By averaging over a representative zone (to be specified later on), $P_{\mathrm{o}}$ is assumed to be equal to the damage variable $D$. It is interesting to note that the first order approximation of Eqn. (8) leads to the differential equation proposed by Grady and Kipp [16] to describe the kinetics of an isotropic damage variable. By using Eqns. (1), (6) and (8), the change of the damage parameter is written as

$$
D=1-\exp \left[-\frac{m ! n !}{(m+n) !} \bar{\sigma}^{m+n}\right]
$$

Equation (14) shows that $D(\bar{\sigma}=1) \cong 0$ and $D(\bar{\sigma}=2) \cong 1$ (i.e., most of the damage evolution occurs during a time interval equal to $t_{\mathrm{c}}$ ). During $t_{\mathrm{c}}$, the horizon is limited by $Z_{\mathrm{o}}\left(t_{\mathrm{c}}\right)=Z_{\mathrm{c}}$ therefore the minimum measure of the representative zone is $Z_{\mathrm{c}}$. By noting that the applied stress $\Sigma$ is related to the local (or effective) stress $\sigma$ by $\sigma=\Sigma /(1-D)$ [36], the ultimate strength $(\mathrm{d} \Sigma / \mathrm{d} \sigma=0)$, denoted by $\Sigma_{\max }$, is expressed as

$$
\frac{\Sigma_{\max }}{\sigma_{\mathrm{c}}}=\left[\frac{1}{\mathrm{e}} \frac{(m+n-1) !}{n ! m !}\right]^{\frac{1}{m+n}} .
$$

Equations (13) and (15) define two different regimes. The first one is obtained when a weakest link hypothesis is made. It corresponds to single fragmentation. The second one assumes multiple fragmentation.

The transition between 'quasi-static' and 'dynamic' strength can be estimated by the intersection between the weakest link and the multiple fragmentation solutions (see Fig. 3)

$$
\sigma_{\mathrm{w}}=\Sigma_{\max }(\dot{\sigma})
$$


The transition defined by Eqn. (16) leads to the following inequalities

$$
\begin{cases}\frac{Z}{Z_{\mathrm{c}}(\dot{\sigma})}<g(m) \quad \text { stress rate independent regime } \\ \frac{Z}{Z_{\mathrm{c}}(\dot{\sigma})} \geq g(m) \quad \text { stress rate dependent regime }\end{cases}
$$

with

$$
g(m)=\left[\frac{\mathrm{e} m ! n !}{(m+n-1) !}\right]^{\frac{m}{m+n}} \Gamma\left(\frac{m+1}{m}\right)^{m} .
$$

When $n=3$ and $m \geq 1.5$, the function $g$ is less than 1. Consequently, an upper bound to the stress rate independent regime is given by $Z=Z_{\mathrm{c}}$. The size $Z_{\mathrm{c}}$ can also be considered as the characteristic scale for which a quasi-static / dynamic fragmentation transition, and a stress (or strain) rate sensitivity is observed. This characteristic parameter can be used in FE computations in which the mesh size has to be greater than or equal to $Z_{\mathrm{c}}$ to use a continuum (and deterministic) description of damage.

\section{Multi-Scale Damage Model}

The state potential is assumed to be given by the Gibbs' specific enthalpy $\Phi$. It is expressed as a function of the macroscopic stress tensor $\boldsymbol{\Sigma}$ and the damage variables $D_{1}, D_{2}$ and $D_{3}$ related to cracking in three orthogonal directions

$$
\rho \Phi=\frac{1}{2} \Sigma: \mathcal{S}: \Sigma
$$

where $\mathcal{S}$ is the compliance tensor dependent upon three damage variables $D_{1}, D_{2}$ and $D_{3}$ associated with three perpendicular cracking directions, $\rho$ the mass density and ':' the contraction wrt. two indices. The associated forces are defined as

$$
\boldsymbol{E}=\rho \frac{\partial \Phi}{\partial \boldsymbol{\Sigma}}=\mathcal{S}: \boldsymbol{\Sigma} \text { and } Y_{i}=\rho \frac{\partial \Phi}{\partial D_{i}}=\frac{1}{2} \boldsymbol{\Sigma}: \frac{\partial \mathcal{S}}{\partial D_{i}}: \boldsymbol{\Sigma}
$$


where $\boldsymbol{E}$ denotes the strain tensor and $Y_{i}$ the energy release rate density associated to the damage variable $D_{i}(i=1,2,3)$. The compliance tensor $\mathcal{S}$ is expressed as (Voigt's notations are used)

$$
\mathcal{S}=\frac{1}{E}\left[\begin{array}{cccccc}
\frac{1}{1-D_{1}} & -\nu & -\nu & 0 & 0 & 0 \\
-\nu & \frac{1}{1-D_{2}} & -\nu & 0 & 0 & 0 \\
-\nu & -\nu & \frac{1}{1-D_{3}} & 0 & 0 & 0 \\
0 & 0 & 0 & \frac{1+\nu}{\left(1-D_{2}\right)^{\alpha}\left(1-D_{3}\right)^{\alpha}} & 0 & 0 \\
0 & 0 & 0 & 0 & \frac{1+\nu}{\left(1-D_{3}\right)^{\alpha}\left(1-D_{1}\right)^{\alpha}} & 0 \\
0 & 0 & 0 & 0 & 0 & \frac{1+\nu}{\left(1-D_{1}\right)^{\alpha}\left(1-D_{2}\right)^{\alpha}}
\end{array}\right] .
$$

where the constant $\alpha$ is a function of the Poisson's ratio $\nu$ (when $\nu=0.15, \alpha \approx$ 0.31 [21]). The kinetics of each damage variable $D_{i}$ is based upon the defect density $\lambda_{\mathrm{t}}$ (no index summation is used)

$$
\frac{\mathrm{d}^{2}}{\mathrm{~d} t^{2}}\left(\frac{1}{1-D_{i}} \frac{\mathrm{d} D_{i}}{\mathrm{~d} t}\right)=n ! S\left(k C_{0}\right)^{n} \hat{\lambda}_{\mathrm{t}}\left[\sigma_{i}(t)\right] \text { when } \frac{\mathrm{d} \sigma_{i}}{\mathrm{~d} t}>0 \text { and } \sigma_{i}>0
$$

The cracking velocity $k C_{0}$ is about $20-40 \%$ the longitudinal wave velocity $C_{0}$ (i.e., $k$ is ranging between 0.2 and 0.4 ), and $S$ is a dimensionless shape factor: in $3 \mathrm{D}$ situations $S \approx 3.74$ [21]. The so-called multi-scale model, uses a modified kinetics of the defect density (see also Ref. [20])

$$
Z_{\mathrm{FE}} \hat{\lambda}_{\mathrm{t}}\left[\sigma_{i}(t)\right]= \begin{cases}0 & \text { if } \sigma_{i}(t) \leq \sigma_{\mathrm{k}}, \\ \max \left[Z_{\mathrm{FE}} \lambda_{0}\left(\frac{\sigma_{i}(t)}{\sigma_{0}}\right)^{m}, 1\right] & \text { otherwise. }\end{cases}
$$

where $\sigma_{\mathrm{k}}$ is the failure stress of the first defect able to break. This failure stress $\sigma_{\mathrm{k}}$ is randomly generated according to a Weibull law (3) when $Z=Z_{\mathrm{FE}}$, 
where $Z_{\mathrm{FE}}$ is the volume of the considered finite element. The multi-scale model is therefore obtained by modeling the failure of the first defect able to break (which is scale-dependent, i.e., mesh size dependent) in addition to the deterministic description of damage used in the continuous model. The probabilistic nature of flaw nucleation then leads to numerical simulations that may vary between two different realizations. Once the elastic properties and the Weibull parameters are known, the model has no other parameters to tune.

An approximate closed-form solution can be derived. In Eqn. (23), one can assume that when the applied stress $\sigma$ is less than $\sigma_{\mathrm{k}}$, the density $\hat{\lambda}_{\mathrm{t}}$ is equal to $\mathrm{O}$. As soon as $\sigma$ becomes equal to $\sigma_{\mathrm{k}}$, the density $\hat{\lambda}_{\mathrm{t}}$ is equal to $\lambda_{\mathrm{t}}$. Consequently, if $t_{\mathrm{k}}$ denotes the time when $\sigma=\sigma_{\mathrm{k}}$, the damage kinetics is given by

$$
D=1-\exp \left[-Z_{\mathrm{o}}\left(T-t_{\mathrm{k}}\right) \lambda_{\mathrm{t}}\left\{\sigma\left(t_{\mathrm{k}}\right)\right\}-\int_{t_{\mathrm{k}}}^{T} Z_{\mathrm{o}}(T-t) \frac{\mathrm{d} \lambda_{\mathrm{t}}}{\mathrm{d} t}\{\sigma(t)\} \mathrm{d} t\right] .
$$

When the applied stress rate is constant, Eqn. (23) can be recast as

$$
D=1-\exp \left[-\left(\frac{t_{\mathrm{k}}}{t_{\mathrm{c}}}\right)^{m+n} \frac{m ! n !}{(m+n) !} h(\tau, m, n)\right],
$$

with

$$
\begin{aligned}
\tau & =\frac{T}{t_{\mathrm{k}}}-1 \text { and } \\
h(\tau, m, n) & =(1+\tau)^{m+n}-\left[1+(m+n) \tau+\frac{(m+n)(m+n-1)}{2} \tau^{2}\right]
\end{aligned}
$$

It can be noted that when $t_{\mathrm{c}} / t_{\mathrm{k}} \ll 1$, an ultimate strength equal to $\sigma_{\mathrm{k}}$ and the quasi-static solution is obtained (Eqn. (13)). Conversely, when $t_{\mathrm{c}} / t_{\mathrm{k}} \gg 1$, the dynamic regime is found with no scatter and Eqn. (14) applies so that the ultimate strength is deterministic (see Eqn. (15)). 
The transition between the two regimes is now analyzed for a SiC-100 ceramic. Figure 3 shows the change of the ultimate strength vs. stress rate in a volume $(n=3)$ of measure equal to $1.25 \mathrm{~mm}^{3}$ (see Table 1 ) and subjected to remote tension (i.e., $\dot{\sigma}$ is constant). The dashed lines represent analytical solutions (Eqns. (13) and (15)) while the dots and error bars are Monte-Carlo simulations of an underlying Poisson point process. When a flaw is broken, a zone of stress relaxation is produced following Eqn. (6). The macroscopic stress is therefore equal to $\dot{\sigma} T$ times the fraction of non-relaxed volumes. Each simulation point corresponds to 500 realizations. For a stress rate within $\left[0,500 \mathrm{MPa} \mu \mathrm{s}^{-1}\right]$, the ultimate strength is not modified by the loading rate. Consequently, the 'quasi-static' solution (Eqn. (13)) applies. When $\dot{\sigma}$ increases by approximately one order of magnitude, the ultimate strength follows the 'dynamic' solution (Eqn. (15)). During the transition, the difference between the dashed lines (Eqns. (13) and (15)) and the Monte-Carlo simulations does not exceed $10 \%$. The standard deviation significantly decreases in the case of multiple fragmentation when the stress rate increases. Furthermore, for SiC100 ceramics, a stress rate up to $10 \mathrm{MPa} \times \mu \mathrm{s}^{-1}$ has shown no stress rate effect on the mean failure strength [28]. This observation is in good agreement with the result shown in Fig. 3.

In Fig. 3 are also shown the predictions based upon the simplified multi-scale model. The prediction of the average failure strength is obtained by assuming that the random stress $\sigma_{\mathrm{k}}$ is equal to $\sigma_{\mathrm{w}}$. The corresponding standard deviation is evaluated by computing the failure strength corresponding to the value $\sigma_{\mathrm{k}}=\sigma_{\mathrm{w}}+\sigma_{\mathrm{sd}}$. These calculations lead to reasonable estimates. As expected, 
all results converge for low stress rates towards the closed-form solution given in Eqn. (13). Conversely, for high stress rates all solutions tend towards $\Sigma_{\mathrm{u}}$ expressed in Eqn. (15).

The present model has been validated by two types of edge-on-impact experiments carried out on $\mathrm{SiC}$ ceramics. This set-up was developed by the Ernst-Mach-Institut (EMI) in Germany $[4,1,26]$ and more recently by the Centre Technique d'Arcueil (CTA) in France [37,27]. It can be shown that the same damage mechanism (i.e., damage in tension) is observed in EOI and in real impact configurations [38]. First, a sarcophagus configuration was used to maintain all the fragments and the overall shape of the fragmented zone could be predicted by numerical simulations based upon the simplified damage kinetics given in Eqn. (22) [19]. Second, strains deduced from moiré measurements could also be predicted by the multi-scale damage model of the present section with the damage kinetics given in Eqn. (23) [21]. In both cases, the only parameters used were the elastic properties of the ceramic and the Weibull parameters.

\section{$5 \quad$ Ultimate Strength of Concrete}

The evaluation of dynamic tensile strength of concrete can be obtained by spalling experiments. Goldsmith et al. [39] reported that spalling could be observed in long round specimens made of brittle materials impacted by a steel sphere. To analyze spalling of high performance concrete, Klepaczko and Brara [40] developed a set-up using a split Hopkinson pressure bar impacted on one 
end by a cylindrical projectile (length: $80 \mathrm{~mm}$ ) and on the other a $120 \mathrm{~mm}$ long concrete sample. The tensile loading is uniaxial and 'homogeneous' in the central part of the concrete sample. The range of impact velocity (on the order of $7 \mathrm{~m} / \mathrm{s}$ ) induces strain rates varying between 20 and $120 \mathrm{~s}^{-1}$. Dry and wet concrete samples were tested. The mechanical properties are summarized in Table 1. Figure 4 shows the change of failure stress with strain rate $\dot{\epsilon}=\sigma_{\mathrm{F}} /\left(E t_{\mathrm{F}}\right)$ where $E=42 \mathrm{GPa}$ is the dynamic Young's modulus and $t_{\mathrm{F}}$ the time rise to reach the ultimate stress level $\sigma_{\mathrm{F}}$. A significant strain rate sensitivity is obtained.

The following analysis is performed by using the results of Section 3. Since the Weibull moduli of the two materials are unknown, the experimental data can be used to evaluate them. In a log-log plot, the data can be fitted by a curve of slope $3 /(m+3)$, see Eqn. (15). Very low Weibull moduli are obtained: namely, 1.8 for wet concrete and 2.2 for dry concrete. The two values are of the same order of magnitude, thereby indicating that the defect populations are of the same type, which could be anticipated. The scale parameter $\sigma_{0} \lambda_{0}^{-1 / m}$ is determined by considering the average failure stresses under quasi-static loading condition (namely $4 \mathrm{MPa}$ for wet concrete and $5 \mathrm{MPa}$ for dry concrete with an effective volume of $430 \mathrm{~cm}^{3}$ ). Furthermore, if one assumes that the cracking velocity is equal to $k C_{0} \approx 1600 \mathrm{~m} / \mathrm{s}$ (i.e., $k \approx 0.4$ ), the strength increase can be computed by using Eqn. (15), see Fig. 4. One can note a clear underestimation of the predicted strength compared to experimental data. Among the four parameters of the model (namely, the two Weibull parameters, the shape parameter and the cracking velocity constant $k$ ), the value of $k$ is the least known. Since concrete is a heterogeneous material, one may argue that $k$ is less than values observed for crystalline materials such as ceramics. By con- 
sidering a value $k \approx 0.2$, a good prediction of the strength increase is obtained (Fig. 4) for the two materials.

\section{Ultimate Strength and Toughness of Glass}

In most cases, fragmentation of glass is caused under dynamic loading conditions. Consequently, the relationship between fracture toughness or ultimate strength and loading rate has to be described to model the dynamic behavior of glass. Fracture of glass is mainly characterized by the properties of surface flaws [41]. Bouzid et al. [42] studied damage of glass subjected to different impact conditions by using a split Hopkinson pressure bar and the normalized drop ball test. They show that the 'dynamic' ultimate strength exceeds the static value by one order of magnitude. The time to failure can be linked to the ultimate strength (Fig. 5). By using Eqns. (11) and (15), the ultimate strength depends upon the characteristic time $t_{\mathrm{c}}$

$$
\Sigma_{\max } \propto \sigma_{\mathrm{c}} \propto\left(t_{\mathrm{c}}\right)^{-\frac{n}{m}}
$$

If one assumes that failure is due to surface defects, then $n=2$. By using Eqn. (27), a value $m=3 \pm 2$ is found, which could be characteristic of surface flaws (Table 1).

The model discussed in the previous section predicts a strength increase with the strain or stress rate. In the following analysis, an extension is proposed to analyze the toughness $K_{\text {Ic }}$ sensitivity to the stress intensity factor rate $\dot{K}$. A pre-indented beam is loaded in three-point flexure with different loading rates. The pre-crack has a size of $50 \mu \mathrm{m}[43]$. For low $\dot{K}$, the toughness is constant 
and equal to $0.65 \mathrm{MPa} \sqrt{\mathrm{m}}$. Above $\dot{K} \approx 2 \mathrm{MPa} \sqrt{\mathrm{ms}^{-1}}$ the toughness increases and can double the 'quasi-static' value. Furthermore, the authors note that for low $\dot{K}$, the cracking pattern is made of few radial cracks whereas for higher $\dot{K}$, the crack front is made of numerous radial cracks.

The tendency observed in terms of toughness is similar to that obtained for the strength dependence with stress rate. In the following, it will be assumed that the same hypotheses can be made for the local toughness as for the local strength. In glass, the process zone is very small in the vicinity of the crack tip. Consequently, it is assumed that the cracking sites are located along the crack front and the toughness distribution is assumed to described by a Poisson point process of intensity $\Lambda_{\mathrm{t}}$ per unit length

$$
\Lambda_{\mathrm{t}}(K)=\Lambda_{0}\left(\frac{K}{K_{0}}\right)^{m}
$$

where $m$ is the Weibull modulus, $K$ a local stress intensity factor, $K_{0}$ the scale parameter relative to a reference density $\Lambda_{0}$. When $\dot{K}$ is low enough, the weakest link hypothesis applies and only one site will lead to crack advance with a probability $P_{\mathrm{a}}$

$$
P_{\mathrm{a}}=1-\exp \left[-L_{\mathrm{eff}} \Lambda_{0}\left(\frac{K}{K_{0}}\right)^{m}\right]
$$

where $L_{\text {eff }}$ denotes the effective length. The mean toughness $K_{\mathrm{w}}$ and the corresponding standard deviation $K_{\mathrm{sd}}$ are given by

$$
K_{\mathrm{w}}=\frac{K_{0}}{\left(L \Lambda_{0}\right)^{\frac{1}{m}}} \Gamma\left(1+\frac{1}{m}\right), K_{\mathrm{sd}}^{2}=\frac{K_{0}^{2}}{\left(L \Lambda_{0}\right)^{\frac{2}{m}}} \Gamma\left(1+\frac{2}{m}\right)-K_{\mathrm{w}}^{2} .
$$

The initiation sites are depicted by points in Fig. 6. The first cracking event occurs at time $T_{1}$ and an obscuration zone of length $L_{\mathrm{o}}\left(T-T_{1}\right)$ increasing with time develops. If $\dot{K}$ is high enough, at time $T_{2}$, a second cracking event 
occurs and produces its own obscuration zone. The third and fourth sites do not produce cracking events since they are obscured. Consequently, there is a competition between the loading rate $\dot{K}$ and the obscuration characterized by a propagation velocity $V$ so that $L_{\mathrm{o}}(T-t)$ is expressed as

$$
L_{\mathrm{o}}=2 V(T-t)
$$

which is a function of the present time $T$ and the time to nucleation $t<T$. The occultation probability $P_{\mathrm{o}}$ is now defined by

$$
P_{\mathrm{o}}=1-\exp \left[-\widehat{L}_{\mathrm{o}}(T) \Lambda_{\mathrm{t}}\{K(T)\}\right]
$$

where $\widehat{L}_{\mathrm{o}}$ is the length of the mean obscuration zone

$$
\widehat{L}_{\mathrm{o}}(T) \Lambda_{\mathrm{t}}\{K(T)\}=\int_{0}^{T} L_{\mathrm{o}}(T-t) \frac{\mathrm{d} \Lambda_{\mathrm{t}}}{\mathrm{d} t}\{K(t)\} \mathrm{d} t
$$

Equation (32) is an extension of the results given in Eqn. (8). The probability of obscuration is again used to relate the macroscopic stress intensity factor $\bar{K}$ to the local stress intensity factor $K$ in zones that are not obscured: $\bar{K}=(1-$ $\left.P_{\mathrm{o}}\right) K$. This relationship assumes that the stress intensity factor in obscured zones is vanishing. When more than one cracking event occurs, the maximum propagation toughness $\bar{K}_{\text {Ic }}$ can therefore be related to the rate $\dot{K}$ by

$$
\bar{K}_{\text {Ic }}=K_{c} \exp [-1 /(m+1)]
$$

where $K_{c}$ is the characteristic toughness defined the same way as the characteristic stress (Eqn. (11))

$$
K_{\mathrm{c}}=\left[\frac{K_{0}^{m} \dot{K}}{2 \Lambda_{0} V}\right]^{\frac{1}{m+1}} .
$$

To describe the experimental data shown in Fig. 7 , a Weibull modulus $m \approx 13$ is obtained, an average toughness $K_{\mathrm{w}}=0.65 \mathrm{MPa} \sqrt{\mathrm{m}}$ for an effective length 
$L_{\text {eff }}=40 \mu \mathrm{m}$ and a velocity $V \approx 40 \mu \mathrm{ms}^{-1}$. These parameters allow for a reasonable prediction of the toughness transition observed for soda lime silica glass. It can be noted that this velocity is consistent with the so-called region II in the sub-critical crack growth regime in which crack propagation is controlled by the diffusion of corrosive species to the crack front. The propagation velocity is dependent on the environment and is almost constant in region II [44]. Furthermore the order of magnitude of $V$ is consistent with experimental measurements reported for soda lime silica glass $[45,44]$. The transition rate is predicted to be of the order of $\dot{K} \approx 2 \mathrm{MPa} \sqrt{\mathrm{ms}}-1$. This value is in good agreement with the experimental data of Fig. 7. It can be noted that for rates $\dot{K} \geq 10^{3} \mathrm{MPa} \sqrt{\mathrm{ms}}^{-1}$, the site spacing at saturation is at most on the order of ten nanometers. This result or the saturation in stress intensity factor (Fig. 6c) may explain the overestimation for very high $\dot{K}$.

\section{$7 \quad$ Fragmentation of Ceramics}

The aim of the section is to analyze the single/multiple fragmentation regime for two SiC ceramics (Table 1). The $\mathrm{SiC}-100$ grade is naturally sintered and is not fully dense. No secondary phase can be observed but $\mathrm{B}_{4} \mathrm{C}$ inclusions are present [27] because boron was added to enhance diffusion during sintering. Transgranular failure is the dominant mechanism. SiC-B ceramics are obtained by pressure assisted densification. Aluminum is used to eliminate porosities. An alumina-rich secondary (glassy) phase is present [46]. Because of the lower strength of the secondary phase, the failure mode is predominantly intergranular. 
Transition between the quasi-static and dynamic regimes cannot be studied by using classical flexural tests. The strain velocities that induce a 'dynamic' behavior (as defined in Section 3) cannot be achieved in a flexural test with a hypothesis of equilibrium in the sample. Therefore, the effective volume [Eqn. (5)] may change for different loading rates and no conclusions can be drawn. The 'quasi-static' to 'dynamic' transition can be studied by using EdgeOn-Impact (EOI) configurations. The EOI configuration is used to validate damage evolution laws for numerical simulations of the behavior of dense ceramics $[19,21]$.

For very low impact velocities $(\approx 20 \mathrm{~m} / \mathrm{s})$, only few fragments are produced $[1,26]$ and it corresponds to single fragmentation. With an impact of high velocity $(\geq 500 \mathrm{~m} / \mathrm{s})$, damage is homogeneous in a circular zone propagating in front of the projectile. The ceramic is reduced into powder and the multiple fragmentation regime is achieved. Between the afore-mentioned velocities, an intermediate behavior can be observed. Below a critical velocity depending on the material properties, damage is localized into thinner and thinner corridors when the velocity decreases. This leads us to assume that the corridors are due the transition between dynamic loadings where no localization occurs and quasi-static loadings for which the tile is broken into few pieces. The velocity for which the damage becomes localized in corridors is about $40 \mathrm{~m} / \mathrm{s}$ for $\mathrm{SiC}$ 100 and $185 \mathrm{~m} / \mathrm{s}$ for SiC-B. In the following, criterion (17) is used to examine the validity domain of 'quasi-static' and 'dynamic' fragmentation regimes.

The numerical simulations are performed by using the code Abaqus Explicit [47]. One quarter of $100 \times 100 \times 10 \mathrm{~mm}^{3}$ tiles is modelled with cubic elements of size $1.25 \mathrm{~mm}^{3}$. The so-called multiscale model is used, i.e., the failure of the first defect in each FE cell is random and defined by Eqn. (23). It can 
be noted that for each numerical simulation, the set of random numbers is characterized by an integer called the 'seed' of the random generator [48]. A given probabilistic simulation is then defined by this integer and can always be reproduced by using the same 'seed'.

For the two SiC grades, two simulations with different velocities are performed. For a first velocity of $\approx 500 \mathrm{~m} / \mathrm{s}$, no localization is expected for the two grades. For the second velocity $(\approx 200 \mathrm{~m} / \mathrm{s})$, SiC-B experienced localized damage whereas damage remains homogeneous in $\mathrm{SiC}-100$. The numerical simulations for the $\mathrm{SiC}-\mathrm{B}$ grade are in good agreement with the general shape of the damaged zone experimentally observed. In Fig. 8-a (impact velocity: 185m/s) the damaged zone in front of the projectile that widens and progressively localizes into corridors is well reproduced by the simulation. One can observe that thin corridors have a tendency to follow the mesh direction (see the center of the tile). This is a classical drawback when isolated cracks are modelled by the failure of FE elements. Damage localization disappears for impact velocities greater than $\approx 350 \mathrm{~m} / \mathrm{s}[26]$, as shown in Fig. 8-b for an impact velocity of $513 \mathrm{~m} / \mathrm{s}$. The above mentioned transition associated with damage localization is not observed for $\mathrm{SiC}-100$ (see Fig. 8-c and $-\mathrm{d}$ ) both experimentally and numerically. For the two velocities, the damage front remains circular.

The quasi-static/dynamic criterion is now used to analyze the difference in damage front between SiC-B and SiC-100 grades. The transition does not only depend upon material (Weibull) parameters but also involves the size $Z=Z_{\mathrm{FE}}$ of the considered element and the applied stress rate $\dot{\sigma}$. The response of a large structure can be considered as 'dynamic' for low stress (or strain) rates even though the same material follows the weakest link hypothesis for the same loading applied on a smaller volume. There is therefore no intrinsic 
relationship between material parameters and characteristic scales to describe the fragmentation of brittle materials. This is evidenced by the transition criterion written for a zone of measure $Z$ submitted to a uniform stress rate $\dot{\sigma}$ (see Eqns. (17) and (11))

$$
\left\{\begin{array}{l}
\dot{\sigma}<\sigma_{\mathrm{w}}\left(\frac{Z_{\mathrm{eff}}}{Z}\right)^{1 / m} k C_{0}\left(\frac{S}{Z}\right)^{1 / n} f(m) \quad \text { quasi-static solution } \\
\dot{\sigma} \geq \sigma_{\mathrm{w}}\left(\frac{Z_{\mathrm{eff}}}{Z}\right)^{1 / m} k C_{0}\left(\frac{S}{Z}\right)^{1 / n} f(m) \quad \text { dynamic solution }
\end{array}\right.
$$

with

$$
f(m)=\left[\mathrm{e} \frac{m ! n !}{(m+n-1) !}\right]^{1 / n} \Gamma^{m / n}\left(\frac{m+1}{m}\right) .
$$

The stress rates are calculated by using Eqns. (36) and (37) for a volume of $1 \mathrm{~cm}^{3}$ and the material parameters given in Table 1 . Contrary to the expected result, the two stress rates are comparable for the two $\mathrm{SiC}$ ceramics (Fig. 9). Consequently, localization cannot be related to the single/multiple failure transition. A more detailed observation of the experimental results of Fig. 8 shows that a corridor contains a high density of cracks, corresponding to a high (local) stress rate. Moreover, an analysis of the computed stress rate generated during an impact at $185 \mathrm{~m} / \mathrm{s}$ shows that the local stress rate at the corridor tips remains greater than the transition stress rate. This enables us to conclude that localization into corridors is not a transient phenomenon between quasi-static and dynamic fragmentation. Furthermore, it can be noted that the strength of the $\mathrm{SiC}-\mathrm{B}$ grade is $50 \%$ greater than that of $\mathrm{SiC}-100$, for the same effective volume. The localization into corridors is therefore the only mechanism that allows for stress concentrations (at the tip of the corridor) leading to the failure of the ceramic.

In Fig. 9, the three other materials studied herein are shown. For glass, only 
the Weibull parameters corresponding to volume defects can be considered to compare with the other materials; the cracking velocity $k C_{0} \approx 1500 \mathrm{~m} / \mathrm{s}$ [49], i.e., $k \approx 0.26$. It can be noted that above a given curve, a dynamic regime is expected and below a quasi-static regime. As expected, even though concrete can be multiply fragmented for lower stress rates, only one order of magnitude separates MB50 dry concrete to SiC-B ceramics. Furthermore, soda lime silica glass has properties very similar to $\mathrm{SiC}$ ceramics in terms of volume defects. Figure 9 is a map in which all the brittle materials can be compared in terms of transition between a quasi-static and a dynamic regime.

\section{Summary}

In this study, the defects in brittle materials are assumed to be randomly located in the zone and their size distributions to follow a Poisson-Weibull model. A normalization procedure is defined by introducing characteristic quantities such as zone size, time and density of broken defects. The dimensionless kinetic law for all the variables of the model is only dependent on the Weibull modulus. A damage kinetics and description is derived within a Continuum Damage Mechanics framework. The above-mentioned normalization technique is used to discuss the choice of the finite element mesh size. The characteristic volume can be used as a measure of the representative zone, and defines the scale where the problem becomes deterministic.

By using experimental measurements of the strength of glass and concrete, it could be shown that the strain (or stress) rate sensitivity could be predicted by the fragmentation model introduced herein. Further investigations 
are needed to confirm the estimates made since the Weibull moduli of the two materials were not known. Complete FE simulations are needed to describe better the load history that was inferred from the information given by the authors who reported the experiments. Furthermore, an extension of the fragmentation model to account for scatter of toughness can be used to analyze the toughness dependence on stress intensity factor rate. The propagation velocity could be related to sub-critical crack growth controlled by the diffusion of corrosive species to the crack tip.

The multiscale model has been used to analyze the localization of damage into corridors in Edge On Impact tests of two SiC grades. The model is able to reproduce the general shape of the damaged zone in terms of cracking directions, localization of damage into corridors, location of the damaged zone. It has been shown that the localization into corridors cannot be expressed in terms of transition between single and multiple fragmentation regimes.

Finally, the scaling strategy can also be used to compare brittle materials such as ceramics, glasses and concrete. The analysis allows one to discuss the probabilistic-deterministic transition for different materials experiencing fragmentation under dynamic loading conditions. A map was proposed to compare all these materials by computing the stress rate at the transition between the above-mentioned regimes. 


\section{Acknowledgments}

This work was partially funded by DGA and supervised by Drs. C.E. Cottenot and L. Rota at CTA. The support of Saint-Gobain Recherche is also gratefully acknowledged as well as discussions with Dr. R. Gy.

\section{References}

[1] E. Strassburger, H. Senf and H. Rothenhäusler, Fracture Propagation during Impact in Three Types of Ceramics, J. Physique IV coll. C8 [suppl. IV] (1994) 653-658.

[2] P. C. den Reijer, Impact on Ceramic Faced Armor, (PhD thesis, Delft Technical University, 1991).

[3] L. Beylat and C. E. Cottenot, Post Mortem Microstructural Characterization of SiC Materials after Interaction with a Kinetic Energy Projectile, Proceedings SUSI'96 symposium, (1996), 459-468.

[4] U. Hornemann, J. F. Kalthoff, H. Rothenhäusler, H. Senf and S. Winkler, Experimental Investigation of Wave and Fracture Propagation in Glass - Slabs Loaded by Steel Cylinders at High Impact Velocities, (EMI report E 4/84, Weil am Rhein (Germany), 1984).

[5] J. Cagnoux, Déformation et ruine d'un verre pyrex soumis à un choc intense : étude expérimentale et modélisation du comportement, (Thèse d'Etat, University of Poitiers, 1985).

[6] J. S. Rinehart, Dynamic Fracture Strengths of Rocks, Proceedings 7th Symp. Rock Mech., (1965). 
[7] H. K. Kutter and C. Fairhurst, On the Fracture Process in Blasting, Int. J. Rock Mech. Min. Sci. 8 (1971) 181-202.

[8] D. A. Shockey, D. R. Curran, L. Seaman, J. T. Rosenberg and C. F. Petersen, Fragmentation of Rocks under Dynamic Loads, Int. J. Rock Mech. Min. Sci. 11 (1974) 303-317.

[9] R. P. Kennedy, A Review of Procedures for the Analysis and Design of Concrete Structures to Resist Missile Impact Effects, Nucl. Eng. Des. 37 (1976) 183-203.

[10] N. F. Mott, Fragmentation of Shell Cases, Proc. Roy. Soc. Lond A189 (1947) 300-308.

[11] D. E. Grady and M. E. Kipp, Geometric Statistics and Dynamic Fragmentation, J. Appl. Phys. 58 [3] (1985) 1210-1222.

[12] N. Kusano, T. Aoyagi, J. Aizawa, Ueno, H. Morikawa and N. Kobayashi, Impulsive Local Damage Analysis of Concrete Structure by the Distinct Finite Element Method, Nuclear Eng. Design 138 (1992) 105-110.

[13] G. T. Camacho and M. Ortiz, Computational Modelling of Impact Damage in Brittle Materials, Int. J. Solids Struct. 33 [20-22] (1996) 2899-2938.

[14] S. Mastilovic and D. Krajcinovic, High-Velocity Expansion of a Cavity within a Brittle Material, J. Mech. Phys. Solids 47 (1999) 577-600.

[15] H. D. Espinosa, P. D. Zavattieri and S. K. Dwivedi, A Finite Deformation Continuum/Discrete Model for the Description of Fragmentation and Damage in Brittle Materials, J. Mech. Phys. Solids 46 (1998) 1909-1942.

[16] D. E. Grady and M. E. Kipp, Continuum Modeling of Explosive Fracture in Oil Shale, Int. J. Rock Min. Sci. \& Geomech. Abstr. 17 (1980) 147-157.

[17] L. G. Margolin, Elasticity Moduli of a Cracked Body, Int. J. Fract. 22 (1983) $65-79$. 
[18] A. M. Rajendran, Modeling the Impact Behavior of AD85 Ceramic under Multiaxial Loading, Int. J. Impact Eng. 15 [6] (1994) 749-768.

[19] C. Denoual and F. Hild, A Damage Model for the Dynamic Fragmentation of Brittle Solids, Comp. Meth. Appl. Mech. Eng. 183 (2000) 247-258.

[20] W. Benz and E. Asphaug, Impact Simulations with Fracture. I. Method and Tests. Icarus 107 (1994) 98-116.

[21] C. Denoual and F. Hild, Dynamic Fragmentation of Brittle Solids: A Multi-Scale Model, Eur. J. Mech. A/Solids 21 (2002) 105-120.

[22] R. Gulino and S. L. Phoenix, Weibull Strength Statistics for Graphite Fibres Measured from the Break Progression in a Model Graphite/Glass/Epoxy Microcomposite, J. Mater. Sci. 26 [11] (1991) 3107-3118.

[23] D. Jeulin, Modèles morphologiques de structures aléatoires et changement d'échelle, (thèse d'Etat, University of Caen, 1991).

[24] A. M. Freudenthal, Statistical Approach to Brittle Fracture, in: Fracture, H. Liebowitz, Edt., (Academic Press, New York (USA), 1968), 591-619.

[25] D. G. S. Davies, The Statistical Approach to Engineering Design in Ceramics, Proc. Brit. Ceram. Soc. 22 (1973) 429-452.

[26] E. Strassburger and H. Senf, Experimental Investigations of Wave and Fracture Phenomena in Impacted Ceramics and Glasses, (ARL, Report ARL-CR-214, 1995).

[27] P. Riou, C. Denoual and C. E. Cottenot, Visualization of the Damage Evolution in Impacted Silicon Carbide Ceramics, Int. J. Impact Eng. 21 [4] (1998) 225235 .

[28] C. Denoual and P. Riou, Comportement à l'impact de céramiques techniques pour blindages légers, (CREA, Report 95 R 005, 1995). 
[29] L. B. Freund, Crack Propagation in an Elastic Solid Subjected to General Loading - Constant Rate of Extension, J. Mech. Phys. Solids 20 (1972) 129-140.

[30] C. Denoual, G. Barbier and F. Hild, A Probabilistic Approach for Fragmentation of Ceramics under Impact Loading, C. R. Acad. Sci. Paris $\mathbf{3 2 5}$ [Série IIb] (1997) 685-691.

[31] D. Jeulin and P. Jeulin, Synthesis of Rough Surfaces by Random Morphological Functions, Proceedings 3rd European Symposium of Stereology (1981) 239-246.

[32] J. Serra, Image Analysis and Mathematical Morphology, (Academic Press, London (UK), 1982).

[33] A. G. Evans, A Method for Evaluating the Time-Dependent Failure Characteristics of Brittle Materials - and its Application to Polycrystalline Alumina, J. Mater. Sci. 7 (1972) 1137-1146.

[34] H. D. Bui and A. Ehrlacher, Propagation dynamique d'une zone endommagée dans un solide élastique fragile en mode III et en régime permanent, C. R. Acad. Sci. Paris série B [t. 290] (1980) 273-276.

[35] H. D. Bui and A. Ehrlacher, Propagation of Damage in Elastic and Plastic Solids, in: Advances in Fracture Research, D. François, Edt., (Pergamon Press, Oxford (UK), 1982), 533-551.

[36] Y. N. Rabotnov, Creep Problems in Structural Members, (North-Holland, Amsterdam (the Netherlands), 1969).

[37] P. Riou, Contribution à l'étude de l'endommagement du carbure de silicium lors d'un impact de basse énergie : application aux blindages, (PhD thesis, Ecole Nationale Supérieure des Mines de Paris, 1996).

[38] C. Denoual, C. E. Cottenot and F. Hild, On the Identification of Damage during Impact of a Ceramic by a Hard Projectile, Proceedings 16th International Conference on BALLISTICS, (APDS, Arlington, VA (USA), 1996), 541-550. 
[39] W. Goldsmith, M. Polivka and T. Yang, Dynamic Behavior of concrete, Exp. Mech. 6 (1966) 65-79.

[40] J. Klepaczko and A. Brara, An Experimental Method for Dynamic Tensile Testing of Concrete by Spalling, Int. J. Impact Eng. 25 (2001) 387-409.

[41] T. Zarzycky, Glasses and the Vitrous State, (Cambridge University Press, Cambridge (UK), 1991).

[42] S. Bouzid, A. Nyounghe, G. Pluvinage and Z. Azari, Endommagement du verre sous différents modes d'impact, Verre 5 [6] (2000) 26-31.

[43] J. Zongzhe, M. Junarong and L. Xiaorui, Dynamic fracture and Strength of Glass, Proceedings XIVth Int. Congr. on Glass, (1986), 78-83.

[44] J. Mencik, Strength and Fracture of Glass and Ceramics, (Elsevier, Amsterdam (the Netherlands), Glass Science and Technology, 1992).

[45] C. R. Kurkjian, Edt., Strength of Inorganic Glass (Plenum Press, New York (USA), 1985), VI:11

[46] P. Forquin, C. Denoual, C. E. Cottenot, L. Rota and F. Hild, Experimental Approach and Modeling of the Compressive Behaviour of Two SiC Grades, $J$. Physique IV 10 (2000) Pr9-735-740.

[47] H. D. Hibbitt, B. I. Karlsson and P. Sorensen, Abaqus User's manual, ABAQUS/EXPLICIT, (version 5.8, Volume I et II, 1998).

[48] W. H. Press, S. A. Teukolsky, W. T. Vetterling and B. P. Flannery, Numerical Recipes in $C$, (Cambridge University Press, Cambridge (UK), 1992).

[49] T. Zarzycky, Glasses and the Vitrous State, (Cambridge University Press, Cambridge (UK) 1991).

[50] K. Cho, N. Katz and I. Bar-On, Strength and Fracture Toughness of Hot Pressed SiC Materials, Ceram. Sci. and Eng. Proc. 16 (1995). 
[51] R. Palika, Private communication (1995).

[52] D. R. Oakley, An Empirical Study of the Effect of Stressed Area on the Strength of Float Glass Surfaces, J. Non-Cryst. Solids 196 (1996) 134-138.

[53] R. Gy and C. Guillemet, Characterization of a mode of rupture of glass at 610C, in: The Physics of Non-Crystalline Solids, L. D. Pye, W. C. L. Course and H. J. Stevens, Edts., (Taylor \& Francis, London (UK), 1992). 


\section{List of Tables}

1 Material properties of various brittle materials. 
Table 1

Material properties of various brittle materials.

\begin{tabular}{|c|c|c|c|c|c|c|}
\hline Parameters & $\mathrm{SiC}-100^{\sharp}$ & $\mathrm{SiC}-\mathrm{B}^{b}$ & MB50d & $\mathrm{MB} 50 \mathrm{w}^{\natural}$ & $\operatorname{Glass}(\mathrm{S})^{\ddagger}$ & Glass $(\mathrm{V})^{\star}$ \\
\hline Young's modulus $E(\mathrm{GPa})$ & 410 & 455 & 42 & 42 & 70 & 70 \\
\hline Poisson's ratio $\nu$ & 0.15 & 0.16 & 0.21 & 0.21 & 0.22 & 0.22 \\
\hline Density & 3.15 & 3.20 & 2.2 & 2.34 & 2.5 & 2.5 \\
\hline Porosity & $1.8 \%$ & 0 & NA & $\mathrm{NA}$ & 0 & 0 \\
\hline Weibull modulus $m$ & 9.6 & 27 & NA & NA & 7 & 28.5 \\
\hline Mean strength $\sigma_{\mathrm{w}}(\mathrm{MPa})$ & 360 & 560 & 5 & 4 & 100 & 2750 \\
\hline Effective volume or surface & $1.25 \mathrm{~mm}^{3}$ & $1.25 \mathrm{~mm}^{3}$ & $430 \mathrm{~cm}^{3}$ & $430 \mathrm{~cm}^{3}$ & $100 \mathrm{~cm}^{2}$ & $10^{-6} \mathrm{~mm}^{3}$ \\
\hline Number of samples & 65 & 30 & NA & $\mathrm{NA}$ & 400 & 104 \\
\hline Type of test & $\begin{array}{l}3 \text {-point } \\
\text { bending }\end{array}$ & $\begin{array}{l}\text { 4-point } \\
\text { bending }\end{array}$ & tension & tension & $\begin{array}{c}\text { disk } \\
\text { bending }\end{array}$ & tension \\
\hline
\end{tabular}

\#: Ref. [28]

b. Refs. $[50,51]$

घ: Ref. [40], MB50d = MB50 dry, MB50w = MB50 wet

‡: Ref. [52], surface flaws in soda lime silica glass

*: Ref. [53], volume flaws in soda lime silica glass

Hild et al. 


\section{List of Figures}

1 a-Typical sintering defect (see white circle).

b-Weibull plot of a SiC-100 ceramic submitted to three-point flexure.

2 Dimensionless density of broken flaws vs. dimensionless time for three different Weibull moduli $m$.

3 Ultimate strength vs. stress rate. The dots and error bars represent results obtained by Monte-Carlo simulations (500 realizations/point) and their standard deviation for an SiC-100 ceramic. The curves are obtained by using Eqn. (25)

4 Ultimate strength vs. stress rate for dry and wet MB50 concrete measured by Klepaczko and Brara [40] and predicted by using two different values of the cracking velocity factor $k$.

$5 \quad$ Ultimate strength vs. stress rate for soda lime silica glass.

The open symbols are experimental data [42] and the solid line corresponds to the prediction of the 'dynamic' regime [see Eqn. (15)]. 
6 a- Initial crack front and potential cracking site locations $s_{1}, s_{2}, s_{3}, s_{4}$.

b- Cracking and obscuration phenomena. The first initiation occurs for time $T_{1}$ (corresponding to a stress intensity factor $\left.K\left(T_{1}\right)\right)$ at the space location $s_{1}$ and produces an obscured zone $L_{\mathrm{o}}\left(T-T_{1}\right)$ increasing with time. For time $T_{2}$, a second initiation occurs in a non-affected zone $s_{2}$ and produces its own obscured zone. The sites $s_{3}, s_{4}$ are obscured by the first and both first and second sites, respectively. c- Schematic of a crack growth rate plot.

7 Toughness vs. stress intensity factor rate for soda lime silica glass. The solid symbols are experimental data [43] and the solid lines corresponds to the prediction of the 'quasi-static' and 'dynamic' regimes [see Eqns. (30) and (34)].

8 Edge on Impact on SiC-B (a- and b-) and SiC-100 (c- and d-). Pictures (half bottom) were provided by Strassburger and Senf [26]. In the half top view (simulation), the lines depict the crack directions (perpendicular to the direction of the associated damage). The number of cracks is dependent on the nucleated defect density. For high velocity impact $(\approx 500 \mathrm{~m} / \mathrm{s})$, the damaged zone remains circular in front of the projectile. Localization is observed for the SiC-B grade at the velocity of $185 \mathrm{~m} / \mathrm{s}$ whereas the damage front remains circular for the SiC-100 grade. 
9 Transition map [see criterion (36)] where the failure stress rate $\sigma_{\mathrm{w}}\left(\frac{Z_{\mathrm{eff}}}{Z}\right)^{1 / m} k C_{0}\left(\frac{S}{Z}\right)^{1 / n}$ is plotted as a function of the Weibull modulus $m$ for different applied stress rates $\dot{\sigma}$ for five brittle materials $\left(n=3, Z=1 \mathrm{~cm}^{3}\right)$. Above a given curve, a dynamic and deterministic solution applies. Below a given curve, a quasi-static and probabilistic solution applies. 


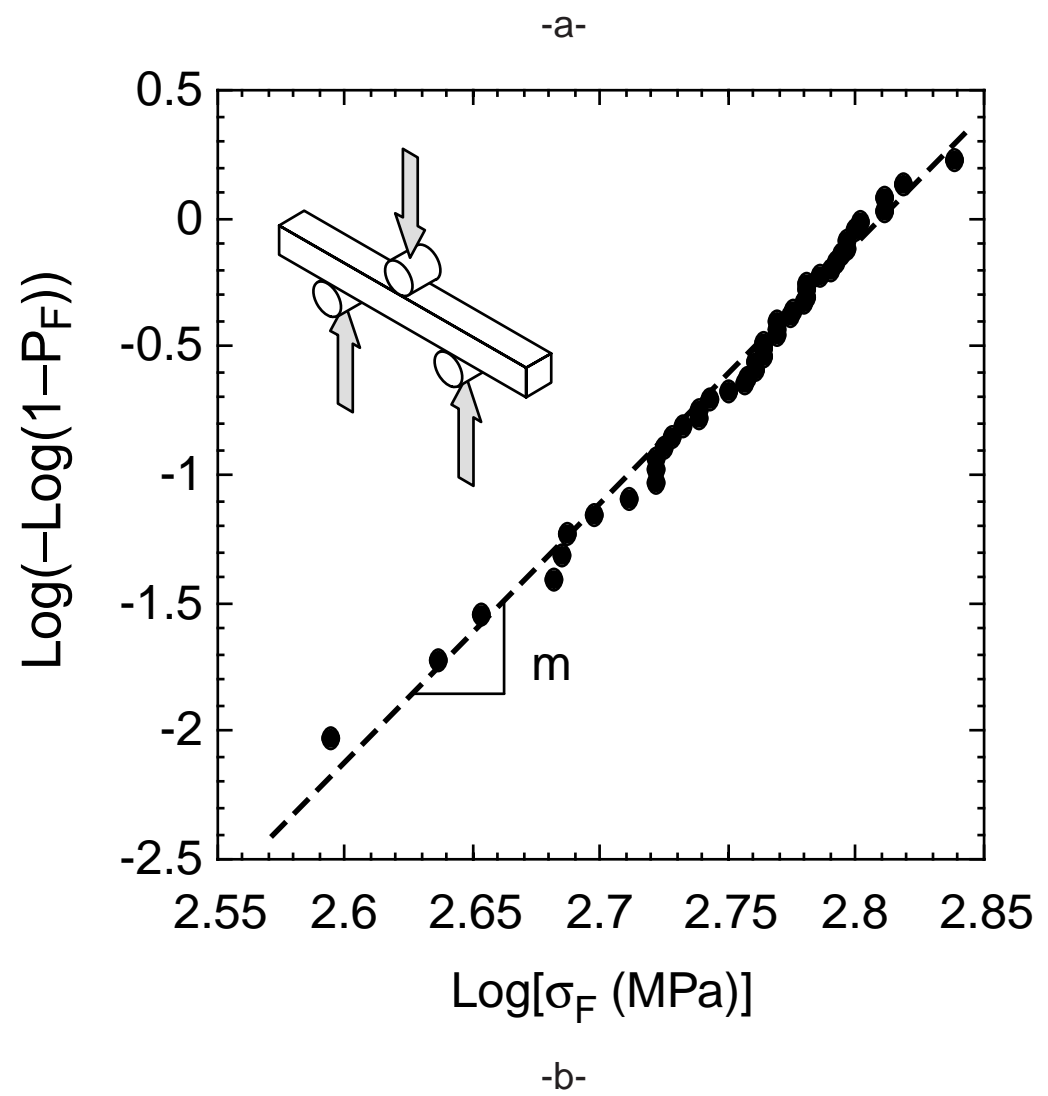

Fig. 1. a-Typical sintering defect (see white circle).

b-Weibull plot of a SiC-100 ceramic submitted to three-point flexure.

Hild et al. 


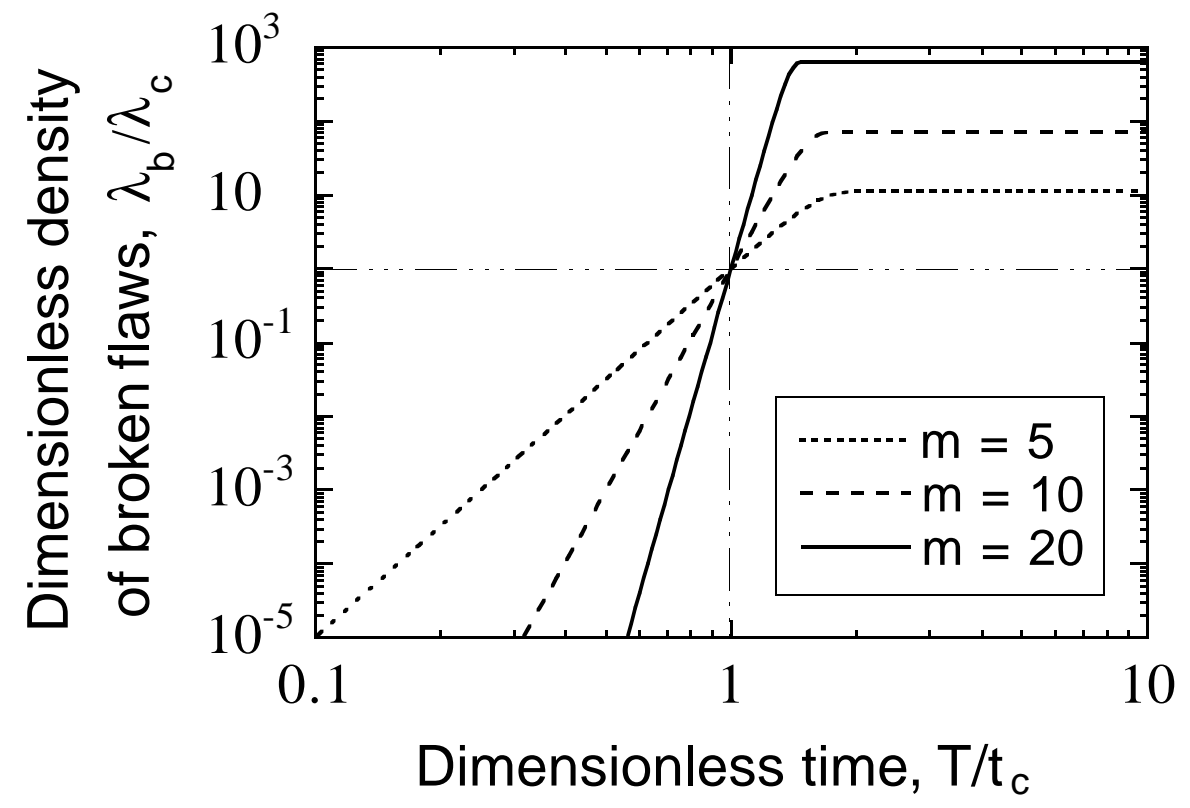

Fig. 2. Dimensionless density of broken flaws vs. dimensionless time for three different Weibull moduli $m$.

Hild et al. 


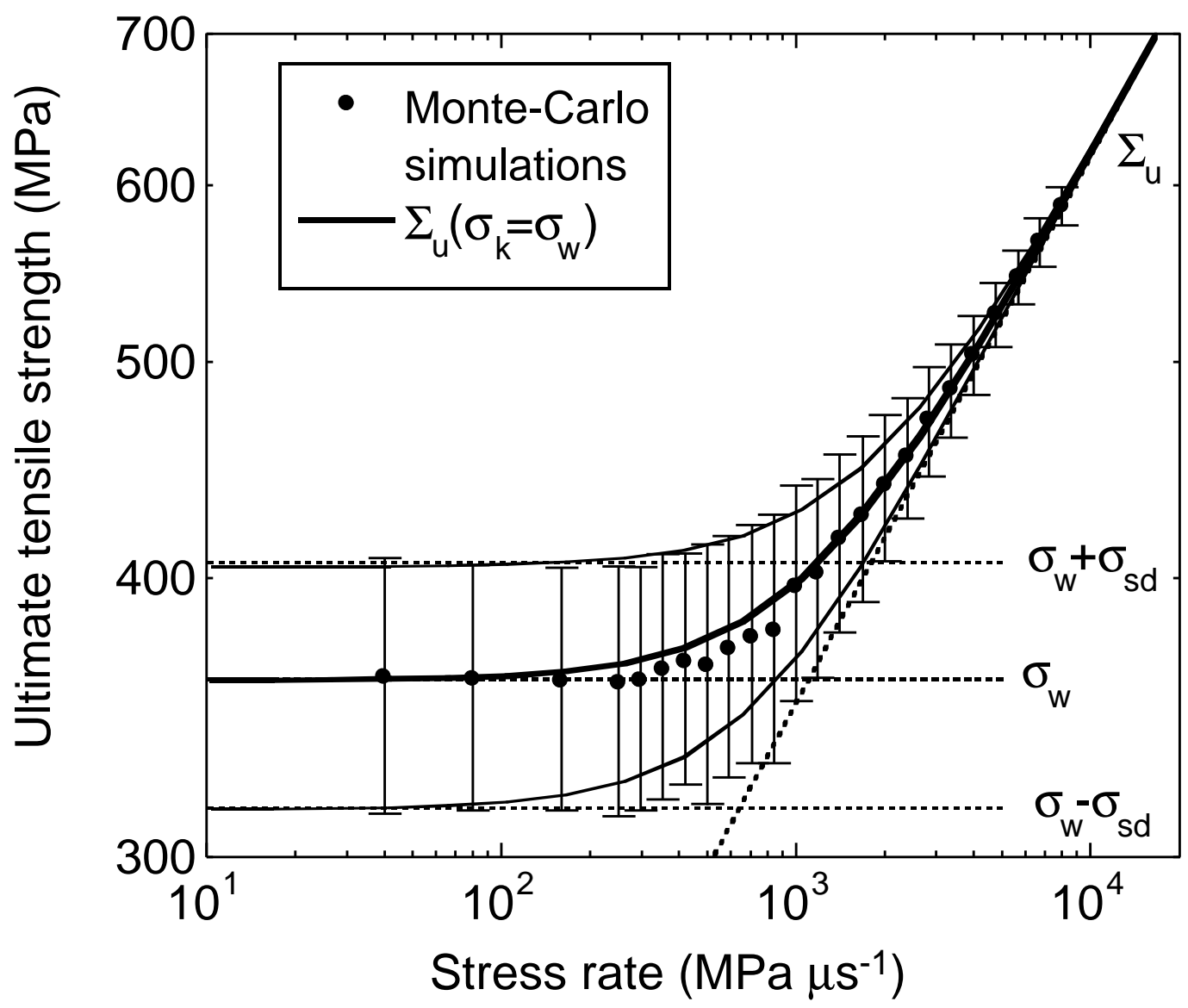

Fig. 3. Ultimate strength vs. stress rate. The dots and error bars represent results obtained by Monte-Carlo simulations (500 realizations/point) and their standard deviation for an SiC-100 ceramic. The curves are obtained by using Eqn. (25)

Hild et al. 


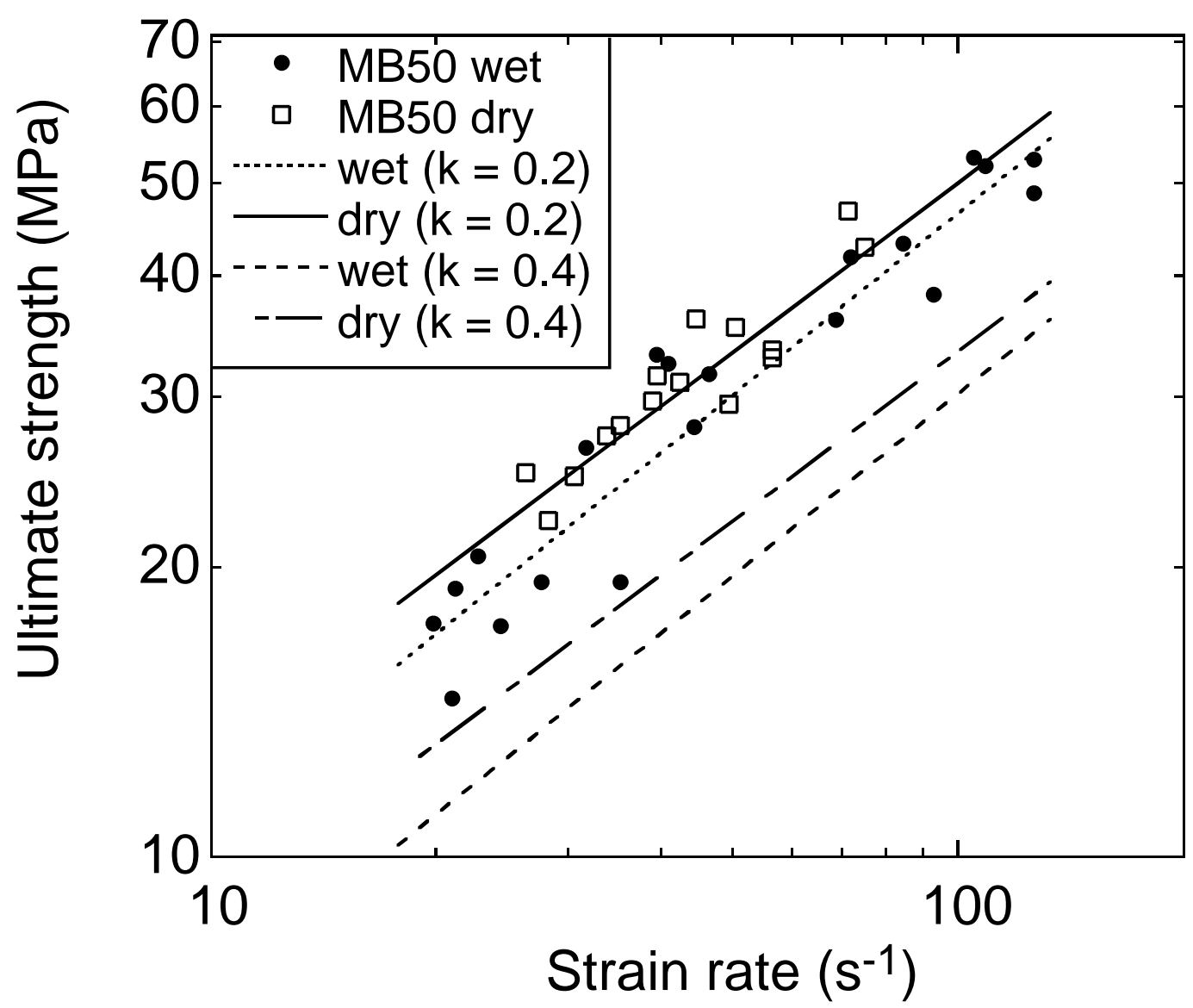

Fig. 4. Ultimate strength vs. stress rate for dry and wet MB50 concrete measured by Klepaczko and Brara [40] and predicted by using two different values of the cracking velocity factor $k$.

Hild et al. 


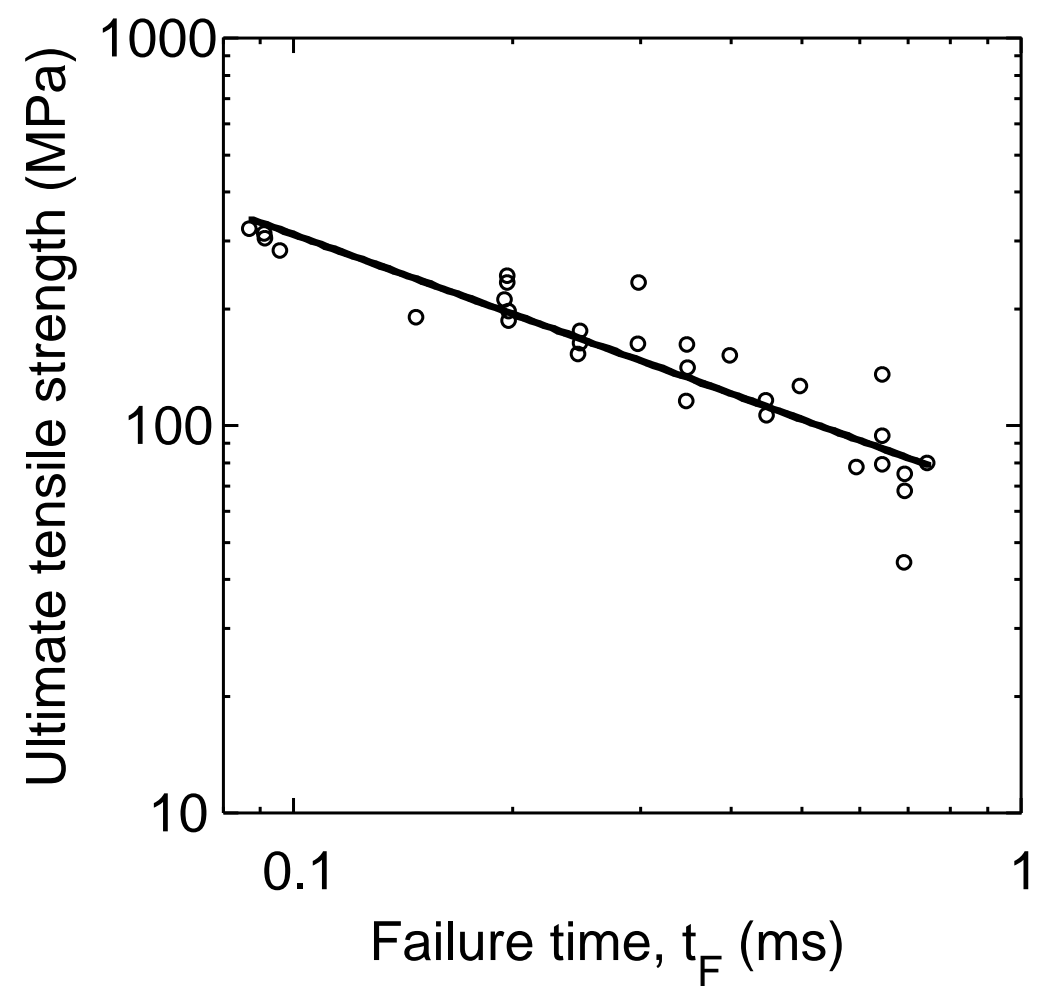

Fig. 5. Ultimate strength vs. stress rate for soda lime silica glass. The open symbols are experimental data [42] and the solid line corresponds to the prediction of the 'dynamic' regime [see Eqn. (15)].

Hild et al. 


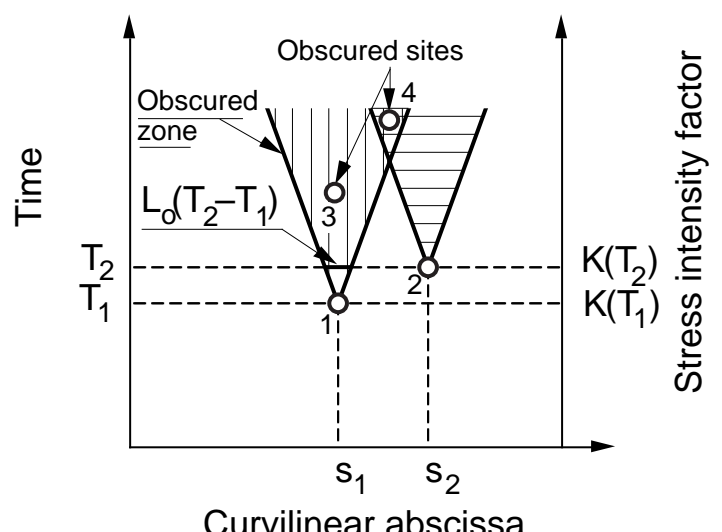

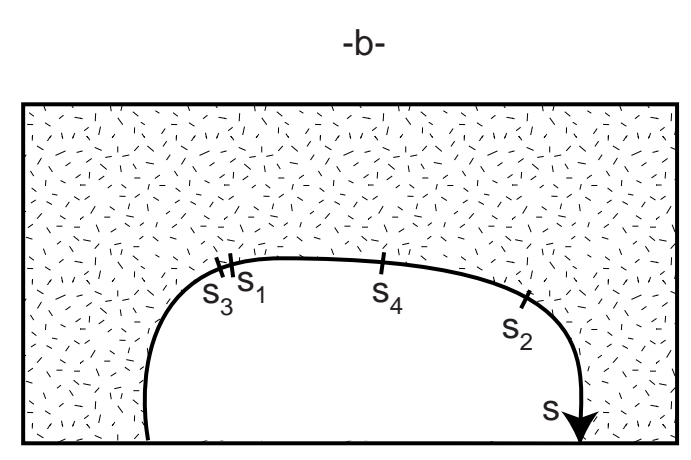

$-a-$

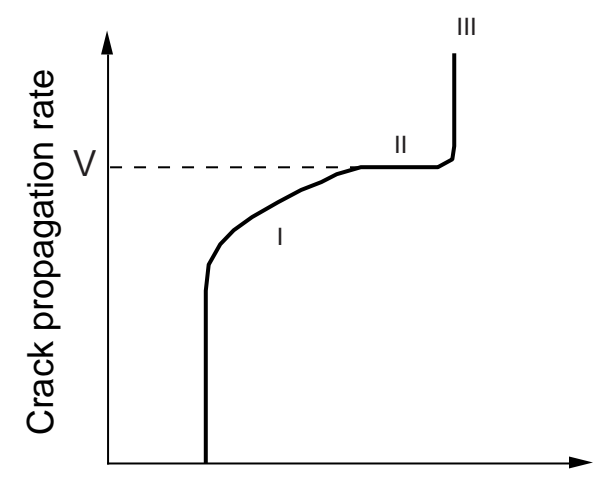

Stress intensity factor

$-\mathrm{C}-$

Fig. 6. a- Initial crack front and potential cracking site locations $s_{1}, s_{2}, s_{3}, s_{4}$.

b- Cracking and obscuration phenomena. The first initiation occurs for time $T_{1}$ (corresponding to a stress intensity factor $K\left(T_{1}\right)$ ) at the space location $s_{1}$ and produces an obscured zone $L_{\mathrm{o}}\left(T-T_{1}\right)$ increasing with time. For time $T_{2}$, a second initiation occurs in a non-affected zone $s_{2}$ and produces its own obscured zone. The sites $s_{3}, s_{4}$ are obscured by the first and both first and second sites, respectively.

c- Schematic of a crack growth rate plot.

Hild et al. 


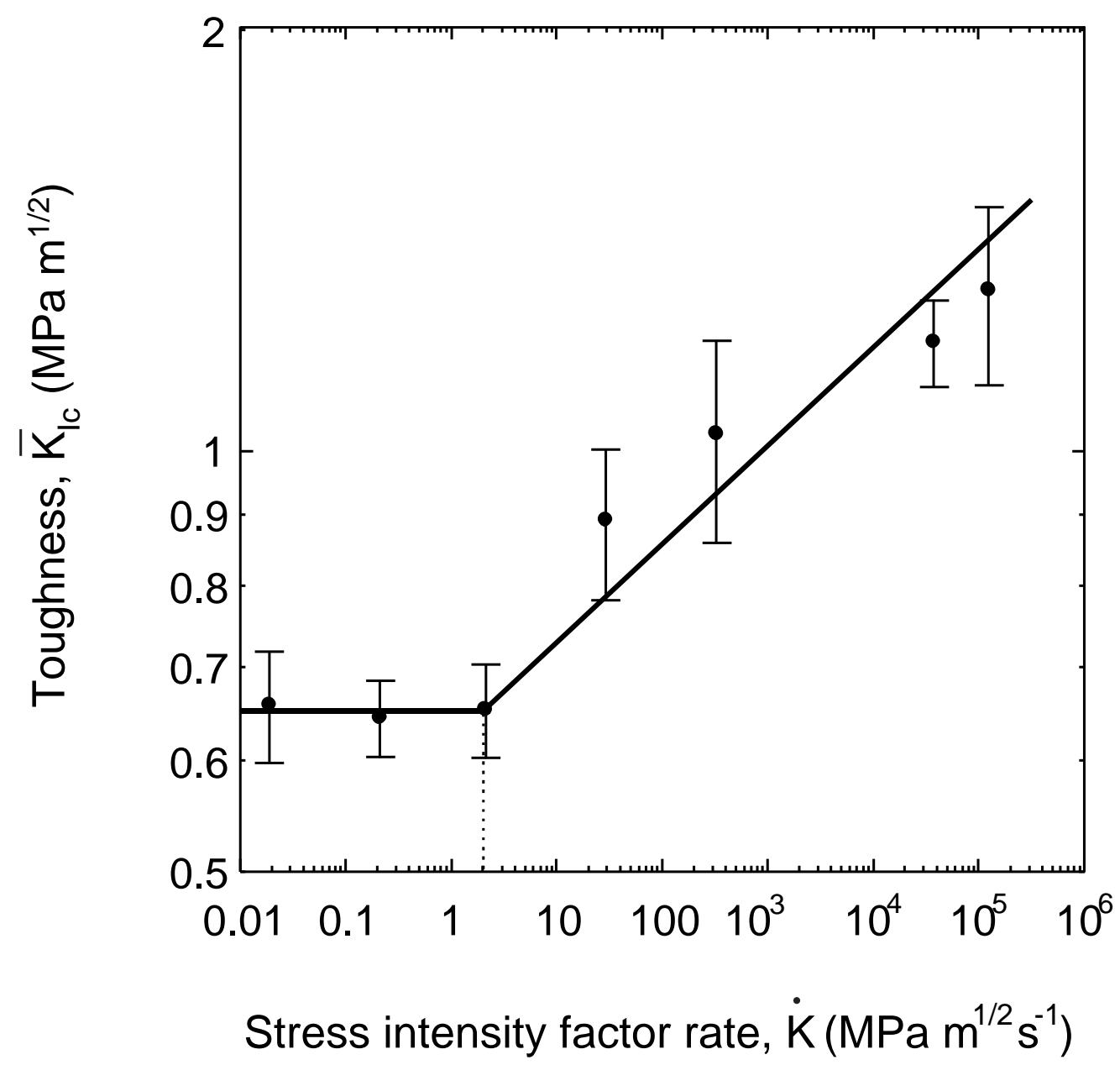

Fig. 7. Toughness vs. stress intensity factor rate for soda lime silica glass. The solid symbols are experimental data [43] and the solid lines corresponds to the prediction of the 'quasi-static' and 'dynamic' regimes [see Eqns. (30) and (34)].

Hild et al. 


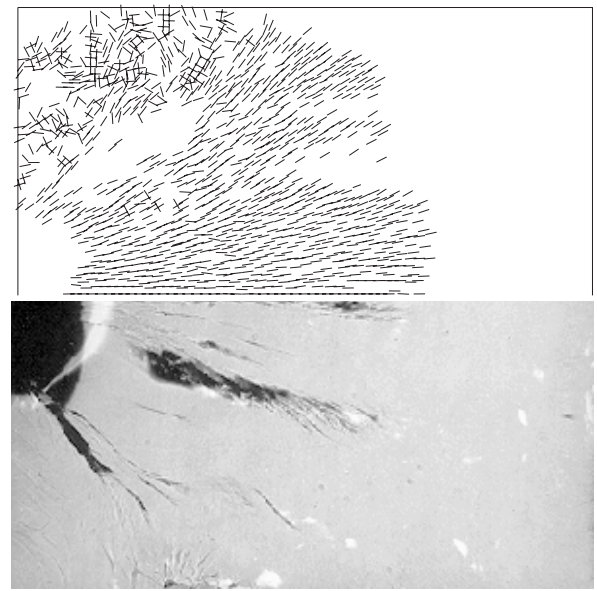

-a- SiC-B $(V=185 \mathrm{~m} / \mathrm{s})$

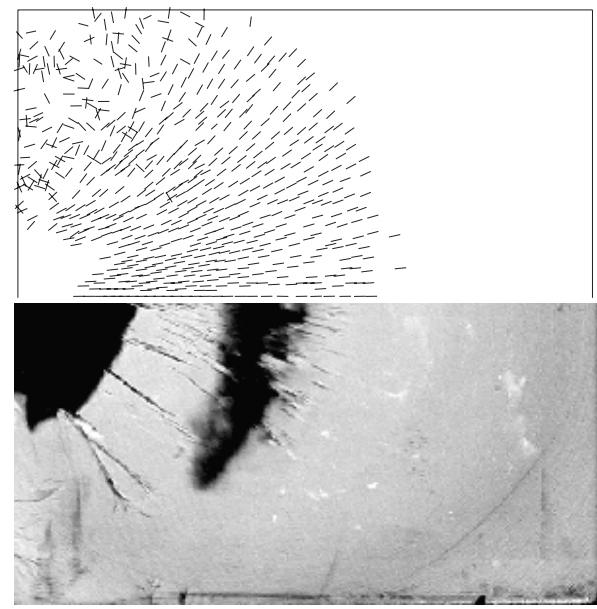

-C- SiC-100 (V = $206 \mathrm{~m} / \mathrm{s})$

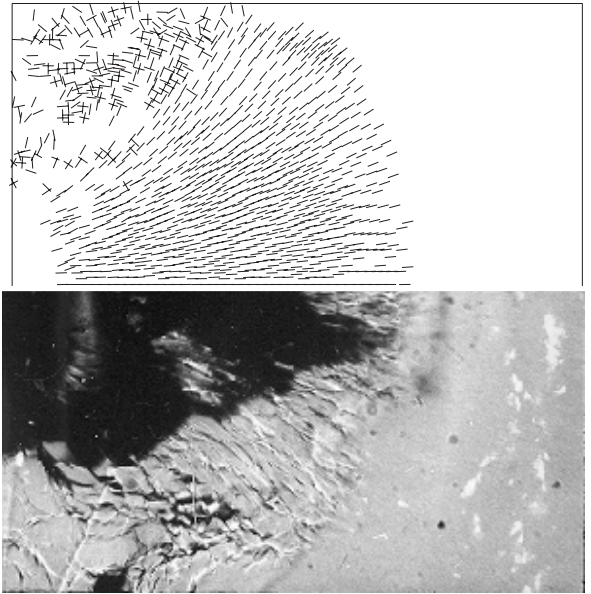

-b- SiC-B $(V=513 \mathrm{~m} / \mathrm{s})$
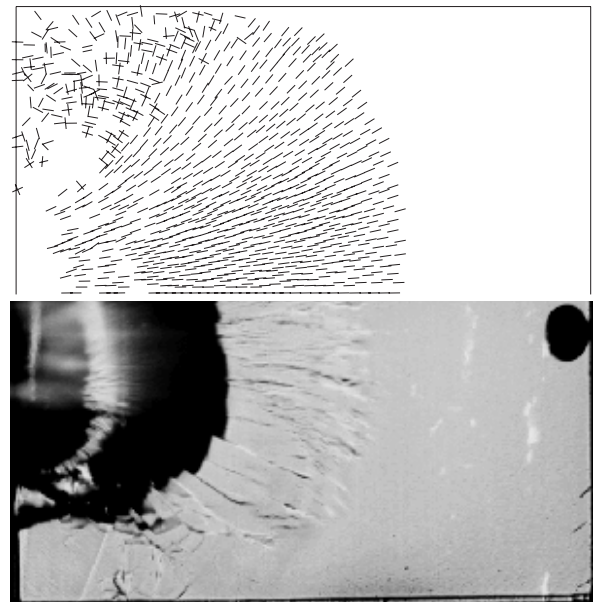

-d- SiC-100 (V = $498 \mathrm{~m} / \mathrm{s})$

Fig. 8. Edge on Impact on SiC-B (a- and b-) and SiC-100 (c- and d-). Pictures (half bottom) were provided by Strassburger and Senf [26]. In the half top view (simulation), the lines depict the crack directions (perpendicular to the direction of the associated damage). The number of cracks is dependent on the nucleated defect density. For high velocity impact $(\approx 500 \mathrm{~m} / \mathrm{s})$, the damaged zone remains circular in front of the projectile. Localization is observed for the SiC-B grade at the velocity of $185 \mathrm{~m} / \mathrm{s}$ whereas the damage front remains circular for the SiC-100 grade.

Hild et al. 


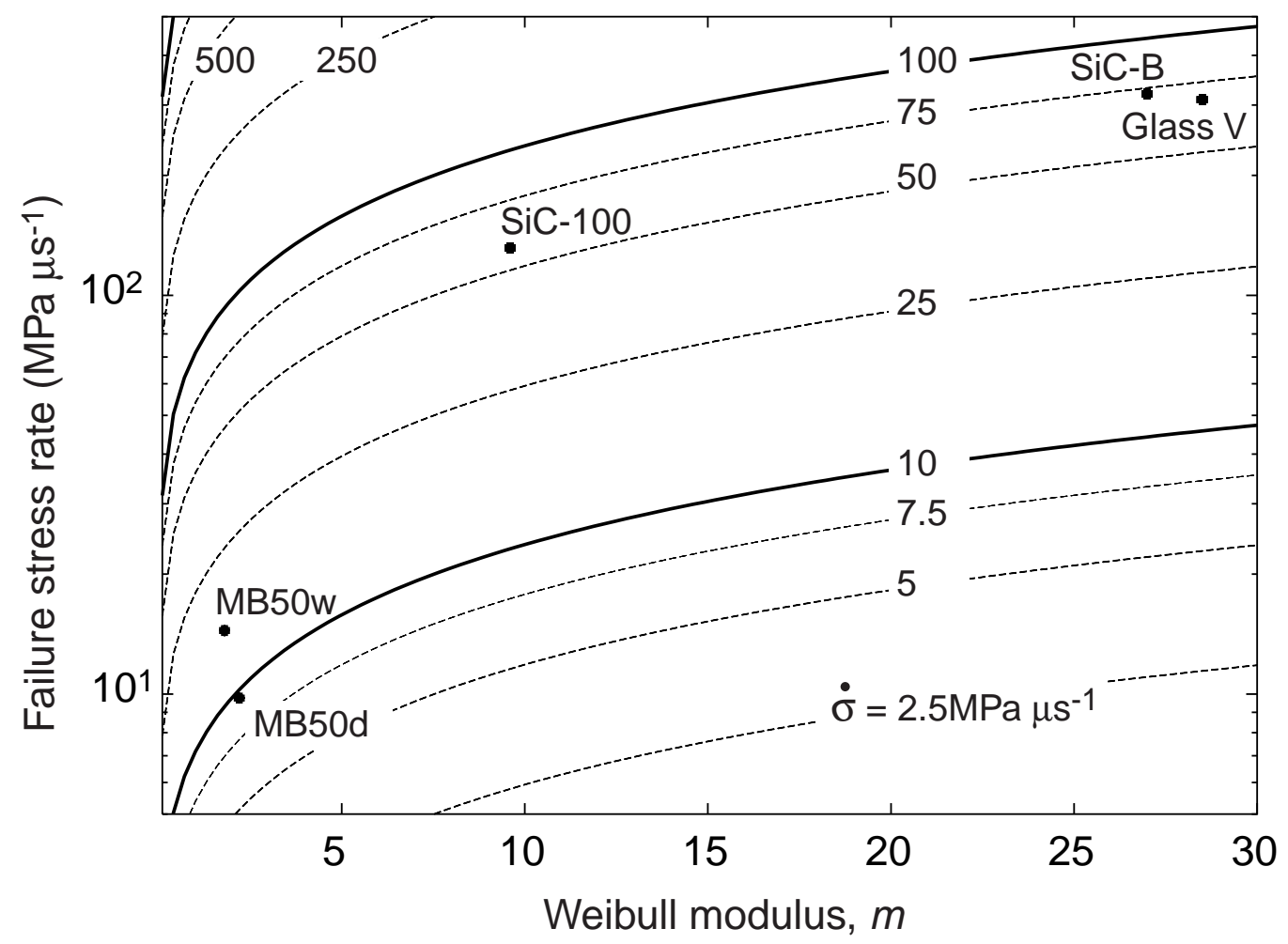

Fig. 9. Transition map [see criterion (36)] where the failure stress rate $\sigma_{\mathrm{w}}\left(\frac{Z_{\mathrm{eff}}}{Z}\right)^{1 / m} k C_{0}\left(\frac{S}{Z}\right)^{1 / n}$ is plotted as a function of the Weibull modulus $m$ for different applied stress rates $\dot{\sigma}$ for five brittle materials $\left(n=3, Z=1 \mathrm{~cm}^{3}\right)$. Above a given curve, a dynamic and deterministic solution applies. Below a given curve, a quasi-static and probabilistic solution applies.

Hild et al. 